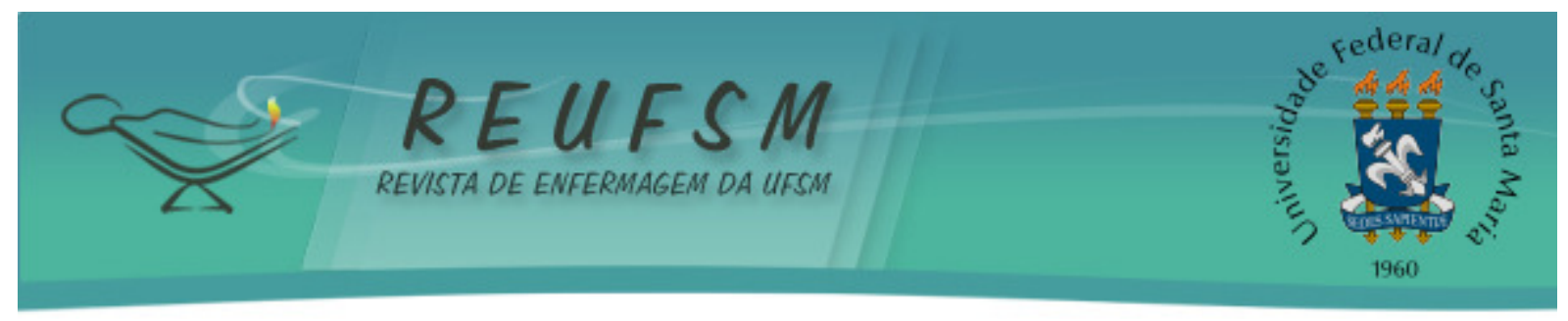

EDITORIAL

\title{
LA IMPORTANCIA DE LA INVESTIGACIÓN EN LOS LENGUAJES ENFERMEROS
}

Paloma Echevarria Pérez ${ }^{1}$

Inicio con gran ilusión esta etapa colaborativa con la revista Revista de Enfermagem da Universidade Federal de Santa Maria - REUFSM, que amablemente me ha invitado a escribir sobre la situación de la Metodología enfermera en España. En un próximo artículo de reflexión lo desarrollaremos desde el grupo de investigación que dirijo en mi universidad y que se denomina "Pensamiento y lenguajes enfermeros en un contexto social". En él investigamos sobre los lenguajes enfermeros de todo tipo, pero nos interesan especialmente aquellos de corte social y cultural.

El título de este editorial lo he elegido incidiendo en el aspecto de la Investigación y no solo en la importancia de los lenguajes enfermeros, ya que en el año 2013 en el que estamos creo que ya no resulta necesario resaltar que el futuro de la profesión va ligado al desarrollo del paradigma y el conocimiento de las taxonomías. Como ya dijo Lang en "Si no lo podemos nombrar, no lo podemos controlar, practicar, investigar, enseñar, financiar o plantearlo en la política pública"1. En lo que quiero incidir es en que, aunque la utilización en la práctica clínica es un reto, y a pesar de que en algunos países se esté aplicando más que en otros, o no se esté aplicando, lo que va a hacer avanzar a la profesión es la investigación. La revolución que supuso la aparición de unas clasificaciones que recogían todo el saber de la enfermería y que sacaban de la invisibilidad muchas de sus actuaciones (ialguien se imaginaba, por ejemplo, que algo que las enfermeras hacen habitualmente como es "Potenciación de la autoestima" o "Escucha activa" pudiera quedar reflejado por escrito?), esa revolución, digo, puede no llegar a nada si no demostramos con veracidad a la sociedad su importancia en cuanto a la evaluación de resultados obtenidos. Puede quedar en algo vacío.

Las organizaciones que han desarrollado las clasificaciones son conscientes de ello. Desde la North American Nursing Diagnosis Association - (Nanda-I) o la Universidad de lowa Nursing Interventions Classification y Nursing Outcomes Classification (NIC-NOC), o desde las organizaciones que trabajan en ellas en cada país o continente, como $A B E n$ (Brasil), AENTDE (España), ASENCIO (Europa), etc. se organizan congresos o simpusium para que se puedan exponer los resultados de las investigaciones. En Brasil se ha celebrado el $11^{\circ}$ Simposio Nacional de Diagnósticos de Enfermería con gran participación. Las revistas de enfermería por su lado cada vez publican de manera más habitual artículos con esta temática, y las universidades preparan master y programas de doctorado en taxonomías. Líneas de investigación que se plantean por ejemplo son: generación de nuevas etiquetas y validación de diagnósticos o intervenciones NIC, operativización y evaluación de Resultados NOC, el proceso de enseñanza de los lenguajes, estudios de implementación, etc.

Los creadores de las clasificaciones han entendido que es una labor mundial, que es un reto a realizar entre TODOS, sin excluir a nadie. Esta es la grandeza del proyecto, aunque a la vez es su debilidad, ya que los contextos culturales son tan dispares que surgen diferencias de interpretación y de aplicación, pero vale la pena seguir trabajando. Hemos empezado hace poco si se piensa desde una perspectiva histórica, pero se están dando pasos muy rápidamente. Internet ha facilitado la comunicación a nivel mundial y este factor hay que aprovecharlo. Desde que empecé a trabajar con los lenguajes no hay un año en el que explique a mis alumnos lo mismo que en el anterior, ya que hay que irse

\footnotetext{
${ }^{1}$ Dra. en Antropología Social y Cultural y enfermera. Decana Facultad de Enfermería, Directora Master Universitario de Investigación en Ciencias Sociosanitarias. Universidad Católica San Antonio. Murcia. España. E-mail: pechevarria@ucam.edu
} 


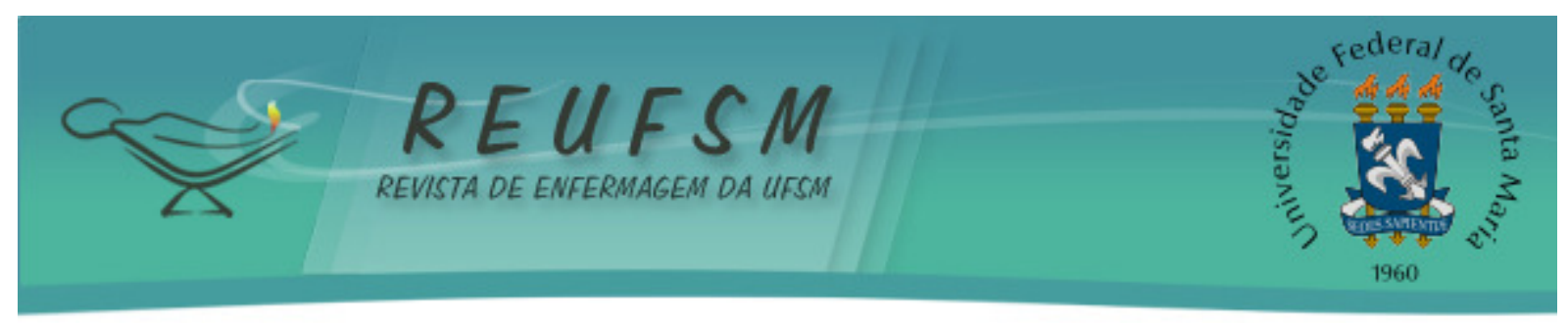

adaptando a lo que va sucediendo. Esto obliga a un enorme esfuerzo de actualización, pero la ilusión también es muy grande al tener la sensación de que todos somos autores de un texto que estamos construyendo.

Referencias:

1 Wake MM, Murphy M, Affara FA, Lang NM, Clark J, Mortensen R. Toward an International Classification for Nursing Practice: a literature review \& survey. Int Nurs Rev. 1993; 40(3):77-80. 